\title{
BMJ Open Key factors influencing the effectiveness of hospital quality management tools: using the quality control circle as an example-a cross-sectional study
}

\author{
Dan Zhang (D), Yue Yan (D), Ting-Fang Liu
}

To cite: Zhang D, Yan Y, Liu TF. Key factors influencing the effectiveness of hospital quality management tools: using the quality control circle as an example-a crosssectional study. BMJ Open 2022;12:e049577. doi:10.1136/ bmjopen-2021-049577

- Prepublication history for this paper is available online. To view these files, please visit the journal online (http://dx.doi. org/10.1136/bmjopen-2021049577).

Received 23 March 2021 Accepted 24 January 2022

Check for updates

(c) Author(s) (or their employer(s)) 2022. Re-use permitted under CC BY-NC. No commercial re-use. See rights and permissions. Published by BMJ.

Institute for Hospital Management,Tsinghua Shenzhen International Graduate School, Tsinghua University, Shenzhen, China

Correspondence to Dr Ting-Fang Liu; liutf@mail.tsinghua.edu.cn

\section{ABSTRACT}

Objective To identify the key factors influencing the effectiveness of hospital quality management tools and analyse the mechanisms needed for long-term scientific hospital management.

Methods In this cross-sectional study, a large number of participants in quality control circle (QCC) activities were investigated on site. Data were collected by the questionnaire during the sixth National Hospital Quality Control Circle Competition in Shandong, China, in October 2018. A total of 1500 participants were randomly selected, in which 1316 questionnaires were completed, yielding an overall response rate of $87.73 \%$, and 1181 questionnaires were valid. We performed a stepwise regression analysis to identify the independent variables with explanatory ability. Then the total mean score of the organisational, group, and individual factors were introduced layer by layer, and a regression model with four levels was established.

Results The application effectiveness of QCC activities can be divided into three dimensions: individual factors, group factors and organisational factors. Utility perception was the most important individual factor. Inappropriate incentives and rewards had a negative effect on both organisational effectiveness and individual effectiveness. The attitude and ability of the circle monitor and counsellors, the specificity of the goals were the key group factors. Of the organisational factors, activity orientation had the greatest impact. Among the three dimensions, individual factors had the most significant influence on the effectiveness of QCCs, followed by group factors, then by organisational factors.

Conclusion These results suggest that addressing the concerns of the leaders and implementing a safeguard system that protects the QCC tool from neglect or failure, that strengthening team building and using team rewards or non-material incentives to enhance enthusiasm, and that mobilising the enthusiasm of the circle members and even the whole hospital for using quality management tools are essential.

\section{INTRODUCTION}

Globally, medical insurance coverage has gradually increased, people's demand for medical treatment has risen rapidly and their awareness of quality and safety has
Strengths and limitations of this study

- This study used a large population and designed specific questionnaires that assess the characteristics of quality control circle (QCC) activity operation and the ways hospitals promoting QCC adoption.

- This study tested the correlations between such a large number of variables in their models and used a hierarchical algorithm to determine whether the factors should be included.

- Data collected from questionnaires and hospital indicators were comprehensively evaluated, whereas most previous studies relied on subjective perceptual data as the dependent variable. The framework of this study will help to focus on future operations and promote the effectiveness of QCC activity.

- The sampling group primarily utilised the participants of the sixth National Hospital Quality Control Circle Competition, ignoring other groups that did not participate in the competition or did not enter the finals.

- As typical cross-sectional research, this study did not establish a cohort or conduct a controlled experiment, which can be inherently biased and confounding.

improved significantly. ${ }^{1}$ As public demand for high-quality medical services increased, governments have also set stricter standards for medical quality. Under the pressure of increasingly stricter regulations and fiercer competition in the medical industry, continually improving medical service quality has become a core competency of medical institutions. ${ }^{2}{ }^{3}$ To promote continuous improvement, a variety of advanced scientific quality management tools and methods, represented in this study by the quality control circle (QCC), have been introduced into the area of healthcare from business or other fields for which they were originally designed. ${ }^{1}$ QCCs are quality improvement teams formed at the initiative of medical personnel and comprise people with similar work duties. A typical team 
has a monitor, a counsellor and three to ten members. Members of the circle analyse the activity flow and steps of their work along with appropriate statistics and quality control techniques to solve existing problems and analyse relevant topics by working and thinking together. The purpose of QCC activities is to optimise methods and propose innovations to achieve the goal of improving medical service quality. ${ }^{4}$ QCC activities benefit medical institutions in several ways: (1) they help to improve the cohesiveness and employee satisfaction of participating work units; (2) they cultivate management skills and increase staff confidence or sense of accomplishment by discovering and handling problems; and (3) they facilitate a harmonious management environment, which can promote continuous improvement in each hospital unit. ${ }^{5}$

In 2016, the National Health and Family Planning Commission of PRC in China's Health Administration Department (currently called the National Health Commission) issued the Medical Quality Management Measures, requiring medical institutions to use management tools for self-evaluation and quality improvement. To promote the application of QCCs in medical institutions, the Institute for Hospital Management of Tsinghua University formed the China Hospital Quality Control Circle Alliance (now renamed the China Hospital Quality Management Alliance) and has held the national Hospital QCC Competition annually since 2013. Nine competitions have been successfully held, and the QCC activities carried out on the Chinese mainland have reached about 60 000, involving more than 1 million medical workers. QCCs have become one of the most popular quality improvement tools for medical workers on China's mainland. Studies have shown that applying appropriate quality management tools can help organisations achieve established goals, ${ }^{3}$ can mobilise the initiative and enthusiasm of medical institutions and can play a vital role in establishing the long-term scientific management of medical institutions and may improve responsiveness to new requirements towards continuous quality improvement. $^{2}$

Although the promotion of QCCs in medical institutions has achieved remarkable results, disputes and misunderstandings about the correct ways to introduce and apply them remain. What are the key factors affecting the effectiveness of QCCs' introduction and application in medical institutions? How does the successful promotion of QCC in medical institutions interact with factors at the organisational, group and individual levels? Numerous studies investigated hospital management tools, but few focused on the effectiveness of their application or on their influencing factors. Previous studies concluded that the factors affecting the effectiveness or implementation of QCCs include organisational, group and individual factors. ${ }^{67}$ Background demographic and baseline hospital information were also taken into account in this research. Some studies showed that the effectiveness of quality tools positively correlated with managerial support and group leadership but that these tools had a poor performance when used with personal reward and feedback systems. ${ }^{4}$ Because the QCC team is a self-managed group, the degree of participation and activeness of the circle members have a significant impact on the circle's effectiveness, and other studies showed that a unified labour-rewarding scheme was able to effectively motivate participating individuals. ${ }^{8}$ This study investigated the key ways that hospitals can use QCC tools to improve quality in the future, examined the effectiveness of QCCs and their relationship with affecting factors as they contribute to understanding the strategies of hospitals in carrying out valuable activities while decreasing resource inputs. The study findings can provide hospital managers with information about the factors that improve quality and thus can facilitate the development of appropriate strategies for improving hospital operations. Our findings can help to prevent the misuse of management tools in medical institutions and improve QCC application efficiency, aid in developing a complete and systematic theory and provide advice for medical institutions that are implementing or ready to use QCCs. Our scale variables indicate the effectiveness of QCCs by investigating the influencing factors from different perspectives. The effectiveness of a QCC was measured in five dimensions. (1) Were positive organisational outcomes, such as improving the hospital image, increasing patient satisfaction, enhancing staff achievement, increasing communication, aiding cooperation between departments, improving service and increasing cost savings, achieved? (2) Were negative organisational outcomes, such as increased work loads after applying the tool, increased staff complaints or treating the circles as a mere formality, reduced? (3) Did the QCCs improve work ability, increase the hospital leadership's cohesiveness, improve problem-solving skills, identify talents, unify the leaders in utlising QCCs effectively and improve quality and safety awareness? (4) Were the staff's mental and physical needs, including improving job satisfaction, encouraging a professional spirit, developing a spirit of cooperation and increasing work achievement, met? (5) Was a hospital management mechanism and culture that promotes the safest possible environment for patients and staff and helps achieve a mechanism for long-term quality management constructed? All of these can be taken as signs of the effectiveness of applying QCCs in a hospital environment.

Therefore, this study hypothesised that greater effectiveness of QCCs is related to active involvement and harmonious cooperation at all levels from the individual to the organisation. Such involvement and cooperation help to increase each member's sense of team honour and of the medical quality of their hospital. For this reason, the present study is based on the concept that, when members care about and are satisfied with QCC activities, such as opportunities to learn new skills (training), willingness to improve the team (activeness), emphasis on quality (values) and work efficiency (utility perception), they will proactively push for greater effectiveness. For the group variables, this study assumed that there were 
positive connections between the effectiveness of QCCs and group factors such as the attitudes and abilities of the circle counsellor and circle monitor, the clarity and specificity of the group objectives and the effective training of QCC skills. With respect to the organisational variables, we investigated whether, when leaders paid more attention to QCCs, provided more systems (eg, rewards, feedback), and strengthened communication and publicity, the effectiveness of the QCC improved.

\section{MATERIAL AND METHODS \\ Questionnaire}

We used a literature analysis and consultation with hospital administration experts to design a questionnaire to assess the organisational, group and individual dimensions and analyse the key factors influencing the effectiveness of QCCs. Two electronic databases, CNKI and WOS (inception to 2018), 23 relevant English-language journals (1984-2018) and 67 Chinese journals (2006-2018) were searched using terms like 'effectiveness' and 'QCC' in the medical field. Studies testing the effectiveness of specific QCCs were included. Two authors independently assessed each study's quality.

The questionnaire went through a committee of judges for content reliability evaluation. In this study, 12 content experts were employed to evaluate and revise the indicators of the questionnaire, and two research coordinators collected experts' opinions and deliberated the sequence and language of the evaluation questionnaire. To ensure that the questionnaire reflected current hospital realities, two hospital vice presidents and three clinicians from Class III Chinese hospitals provided key advice about patients' greatest concerns. To ensure the comprehensiveness and scientific nature of the factors, we consulted five well-known teachers from top-tier Chinese universities,
Tsinghua and Fudan. To assess the feasibility and operability of the items in the questionnaire, we consulted with a vice president from a large limited liability company. Finally, to make sure that the questionnaire was realistic, we worked with the director of the local government. Each expert was asked to make suggestions for altering any of the contents and to justify every factors on the basis of their own experience or common sense.

The literature search showed that scholars from the USA, Germany and Japan have promulgated several factors that may affect the effectiveness of QCCs and other relevant assessment tools. However, most of the studies were only theoretical summaries and practical experience compilations ${ }^{19}$; there were relatively few quantitative research studies and analyses. ${ }^{10}$ The factors that influence the effectiveness of quality management tools are complex and sometimes result from fusing several mechanisms. To understand the mechanism of action and the degree of influence of each factor, we had to first classify and combine various factors as accurately as possible and then carry out the corresponding research.

Our study was designed to investigate the correlation between the changes that occur after QCC implementation and the characteristics of medical institutions that influence these changes. A total of 50 questions included the ones covering (1) background information, (2) QCC activity progress, (3) factors (in three dimensions: organisation, group and individual) influencing the QCC application and (4) subjective evaluations of QCC effectiveness. The research framework is shown in figure 1. Each dimension has four factors. The specific item numbers were 16 in organisational dimension, 18 in group dimension and 16 in individual dimension. The 5-point response Likert scale was used to assess each item in the questionnaire.

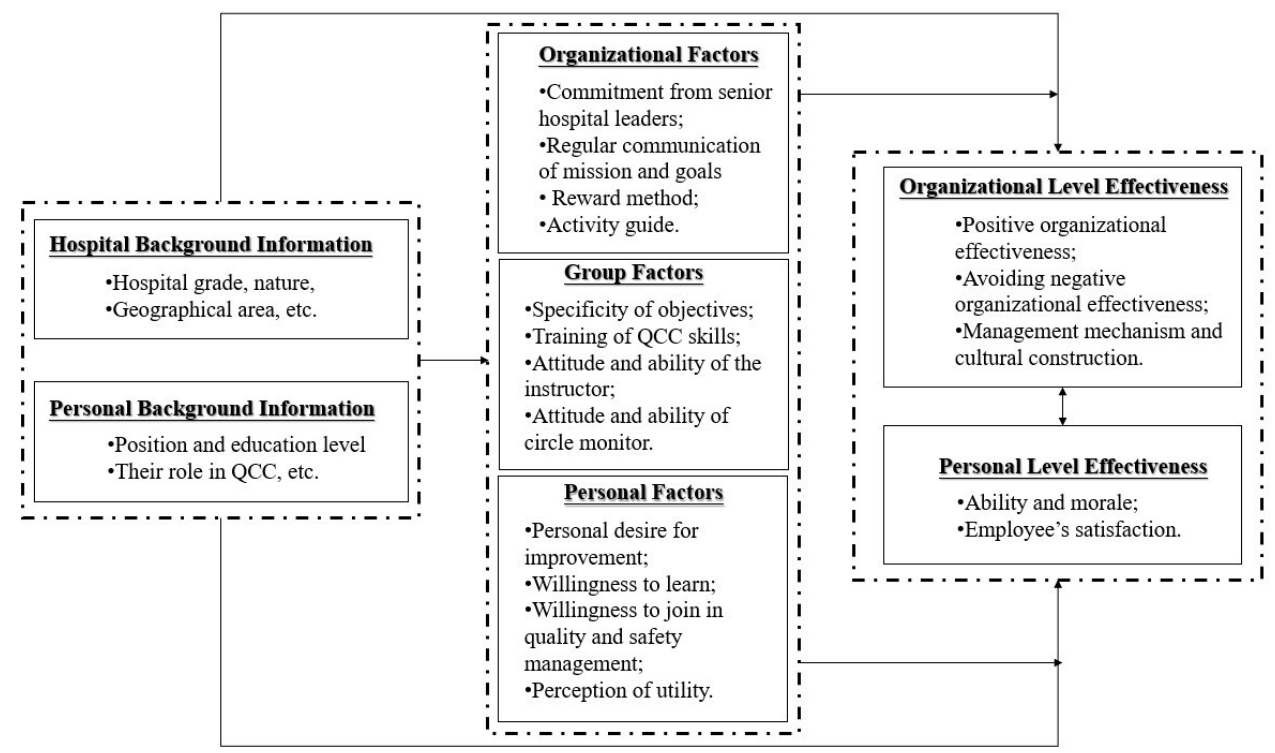

Figure 1 Research framework. This study collected the hospital and the personal background information. Conceptual framework of the determinants of QCC effectiveness can be divided into organisation factors, group factors and personal factors. Finally, the effectiveness is analysed from organisation and personal levels. 
The reliability and validity of the questionnaire were tested by a pre-experiment and then reviewed by professional healthcare experts. The questionnaire in the preliminary experiments randomly selected 100 members from one general hospital in central China that had utilised QCCs to fill in the questionnaire; 89 questionnaires were completed, yielding an overall response rate of $89 \%$. Cronbach's values were above 0.9 for the four dimensions (organisation factors $=0.938$, group factors $=0.916$, individual factors $=0.918$ and application results $=0.916$ ); the aptness of the Kaiser-Meyer-Olkin (KMO) sampling measure was 0.941; and the Bartlett test results were significant $(\mathrm{p}<0.01)$, indicating that this questionnaire had good reliability and validity.

\section{Sample}

\section{Common procedures}

This cross-procedures study was carried out at the sixth National Hospital Quality Control Circle Competition in Shandong, China, in October, 2018. The participants were selected for the survey from people attending the final competition (2996 people). They completed the questionnaires on site. A total of 1500 questionnaires were randomly distributed, 1316 questionnaires were completed, and 1181 questionnaires were valid. Questionnaires were invalid if (1) the questionnaire's positive and negative items appeared to be contradictory, (2) all the checked items in the questionnaire were the same (eg, they chose A for all questions), (3) the topic was not multiple choice, but someone chose more than two options and (4) they filled in more than one questionnaire, as judged by having the same basic information and same answers to the questions. SPSS V.23.0 software was used to statistically process the questionnaire responses. A total of 1500 hospital staff physicians, nurses, technicians (pharmacists, dieticians, laboratory specialists, radiologists and other technicians) and managers were randomly selected. See table 1 for the number in each category.

\section{Patient and public involvement}

The questionnaires handed out in this study were anonymous and voluntary, and written informed consent was received from all participants. Before participants filled in the questionnaire on site, the research group staff would fully inform them of the purpose of the study and how the results would be used. Moreover, there was a questionnaire instruction and informed consent attached before the formal questionnaire content. During the formative research stage, we sought and incorporated feedback from experienced members including Class III hospitals, top-tier universities and local governments. We designed and tested our questionnaires through a preliminary experiment using key stakeholders.

\section{Data processing and statistical analysis}

Two researchers independently input the survey data into Microsoft Office Excel 2017. We used SPSS V.23.0 for Windows to process the data and the descriptive and inferential statistical analyses. We calculated descriptive statistics, such as demographic characteristics, mainly for the frequency and proportion analyses. Inferential statistical methods included hierarchical multiple regression, and stepwise regression.

\section{RESULTS}

A total of 1500 questionnaires were randomly distributed to participants and observers at the sixth National Hospital Quality Control Circle Competition. Of these, 1316 questionnaires were completed, yielding an overall response rate of $87.73 \%$, and 1181 questionnaires were valid, for an effective rate of $89.74 \%$.

\section{Basic respondent demographics}

As shown in table 1, 64.52\% of the participants were women, the average age was 31 years old and $54.53 \%$ were from 30 to 39 years old. Most respondents (64.94\%) had a bachelor's degree. The participants' years in medical practice were most commonly $5-10$ years $(35.06 \%)$. The respondents were mainly from public tertiary hospitals $(81.96 \%)$. The largest number of people were in nursing $(61.98 \%)$. The positions in the circle were dominated by circle members $(75.02 \%)$. Most commonly they had participated in the QCC for an accumulated 1-2 years $(29.70 \%)$. More details of the investigation are shown in table 1 .

\section{Promotion of QCC activities in hospitals}

1. Regulation level: $70.8 \%$ of the hospitals with which the participants were associated had formulated implementation plans or regulations related to QCC activities; $56.7 \%$ of the hospitals had specific incentives for QCC activities, such as start-up funds; $18 \%$ of the medical institutions counted the effectiveness of the QCC into the participant's, their department's and their QCC team's performance assessments.

2. Leading promotional department: the nursing department was responsible for the promotion of QCC activities in $45.5 \%$ hospitals, the quality control department in $18.1 \%, 8.3 \%$ of the hospitals had an exclusive office for QCC activities, the medical department was in charge of $6.5 \%$, the hospital office was responsible for $3.3 \%$ and $6.7 \%$ of the hospitals had no department that was responsible for promoting this activity.

3. Education and training: $65.0 \%$ of hospitals conducted in-hospital training by inviting external experts or lecturers from the hospital to give lectures or training; $56.0 \%$ of the hospitals sent staff to out-of-hospital training; and 3.8\% of hospitals lacked organised training.

Influence of organisational factors on the effectiveness of QCC All dimensions of the Scale of Organisational Factors Affecting the Effectiveness of the Hospital QCCs in the questionnaire were divided into independent variables, and the dimensions of the Scale of Effectiveness 
Table 1 Basic information about the survey samples $(N=1181)$

\begin{tabular}{|c|c|c|c|c|}
\hline \multicolumn{2}{|l|}{ Sample characteristics } & \multirow{2}{*}{$\begin{array}{l}\text { Number } \\
419\end{array}$} & \multirow{2}{*}{$\begin{array}{l}\text { Percentage } \\
35.48\end{array}$} & \multirow{2}{*}{$\frac{\mathbf{P}}{0.172}$} \\
\hline Gender & Male & & & \\
\hline & Female & 762 & 64.52 & \\
\hline & 30-39 years old & 644 & 54.53 & \\
\hline & $40-50$ years old & 172 & 14.56 & \\
\hline \multirow[t]{4}{*}{ Level of formal schooling } & Junior or below & 176 & 14.90 & $<0.001$ \\
\hline & Bachelor degree & 767 & 64.94 & \\
\hline & Master degree & 201 & 17.02 & \\
\hline & Doctor degree & 37 & 3.13 & \\
\hline Fixed number of years of practice & Within 5 years & 296 & 25.06 & $<0.001$ \\
\hline \multirow[t]{4}{*}{ Hospital grade } & Public tertiary hospital & 968 & 81.96 & $<0.001$ \\
\hline & Public level II hospital & 151 & 12.79 & \\
\hline & Civilian battalion hospital & 49 & 4.15 & \\
\hline & other & 13 & 1.10 & \\
\hline \multirow[t]{4}{*}{ Jobs } & Nursing & 732 & 61.98 & $<0.001$ \\
\hline & Physician & 217 & 18.37 & \\
\hline & Technician & 94 & 7.96 & \\
\hline & Logistics & 80 & 6.78 & \\
\hline & $2-3$ years & 235 & 19.90 & \\
\hline & More than 3 years & 300 & 25.40 & \\
\hline \multirow{3}{*}{$\begin{array}{l}\text { Serves the area where the hospital is } \\
\text { located }\end{array}$} & Eastern region & 570 & 48.26 & \\
\hline & Central region & 395 & 33.465 & \\
\hline & Western region & 216 & 18.29 & \\
\hline
\end{tabular}

QCC, quality control circle.

of Hospital QCCs application were divided into dependent variables. Next, stepwise regression analysis was performed by introducing the variables into the model one-by-one, and the independent variables with insignificant explanatory ability were excluded. The significance of the regression model and the explanatory ability of the independent variables to the dependent variables were assessed.

The activity-oriented dimension had the strongest ability to explain the positive organisational effect (table 2), management mechanism and cultural construction of the effectiveness of the QCC activities $(p<0.01)$.
The communication dimension of mission and goals had a significant ability to reduce negative organisational effectiveness $(p<0.01)$. Also, the communication dimension of mission and goals had a significant effect on the improvement of work ability and morale $(\mathrm{p}<0.01)$ as well as on the satisfaction of employees' needs $(p<0.01)$. Based on these results, it is clear that activity-orientation and the communication dimension of mission and goals were the two most critical organisational factor dimensions. Contrary to the hypothesis of the study, the incentives and rewards dimension had a significant $(\mathrm{p}<0.01)$ negative effect on both organisational effectiveness and individual 
Table 2 Influence of the main three factors on the effectiveness of QCC application $(N=1181)$

$\begin{array}{lllllll}\text { Variable } & B & S E B & \beta & R^{2} & \Delta F & \Delta R^{2}\end{array}$

Organisational factors on the effectiveness of QCC application

Taking positive outcomes as the dependent variable

\begin{tabular}{|c|c|c|c|c|c|c|}
\hline \multicolumn{7}{|l|}{ Model 1} \\
\hline Activity-oriented & 0.368 & 0.033 & $0.469^{\star \star}$ & 0.218 & $125.816^{\star *}$ & 0.218 \\
\hline \multicolumn{7}{|l|}{ Model 2} \\
\hline Activity-oriented & 0.243 & 0.038 & $0.310^{\star \star}$ & 0.270 & $32.804^{\star *}$ & 0.052 \\
\hline Communication of mission and goal & 0.279 & 0.049 & $0.281^{\star \star}$ & & & \\
\hline \multicolumn{7}{|l|}{ Model 3} \\
\hline Activity-oriented & 0.384 & 0.058 & $0.490^{\star \star}$ & 0.286 & $10.632^{\star *}$ & 0.016 \\
\hline Communication of mission and goal & 0.311 & 0.049 & $0.313^{\star \star}$ & & & \\
\hline Incentives & 0.174 & 0.053 & $0.239^{\star *}$ & & & \\
\hline
\end{tabular}

Taking negative outcomes as the dependent variable Model 1

\begin{tabular}{|c|c|c|c|c|c|c|}
\hline Communication of mission and goal & 0.338 & 0.058 & $0.268^{\star *}$ & 0.070 & $34.553^{* *}$ & 0.070 \\
\hline \multicolumn{7}{|l|}{ Model 2} \\
\hline Communication of mission and goal & 0.247 & 0.070 & $0.196^{\star \star}$ & 0.079 & $5.357^{*}$ & 0.009 \\
\hline Activity-oriented & 0.127 & 0.055 & $0.128^{\star *}$ & & & \\
\hline \multicolumn{7}{|c|}{ Taking work ability and morale as the dependent variables } \\
\hline \multicolumn{7}{|l|}{ Model 1} \\
\hline Communication of mission and goal & 0.419 & 0.038 & $0.494^{\star \star}$ & 0.209 & $119.241^{* *}$ & 0.209 \\
\hline \multicolumn{7}{|l|}{ Model 2} \\
\hline Communication of mission and goal & 0.278 & 0.045 & $0.325^{\star \star}$ & 0.258 & $30.428^{\star *}$ & 0.049 \\
\hline Activity-oriented & 0.197 & 0.036 & $0.298^{\star *}$ & & & \\
\hline \multicolumn{7}{|l|}{ Model 3} \\
\hline Communication of mission and goal & 0.305 & 0.046 & $0.334^{\star *}$ & 0.271 & $9.119^{\star \star}$ & 0.013 \\
\hline Activity-oriented & 0.318 & 0.054 & $0.442^{\star \star}$ & & & \\
\hline Incentives & 0.150 & 0.050 & $0.223^{\star *}$ & & & \\
\hline
\end{tabular}

Taking employee's satisfaction with demand as the dependent variable

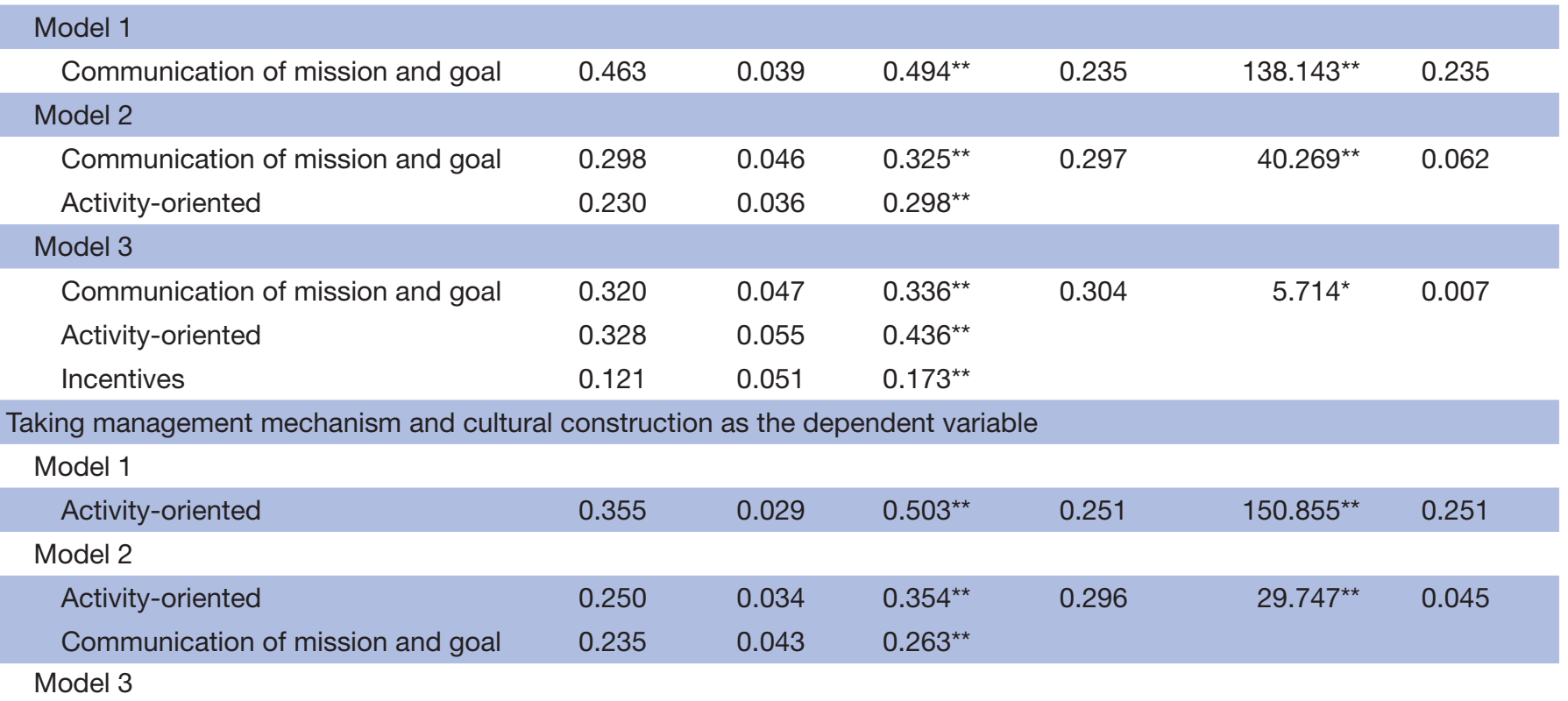


Table 2 Continued

\begin{tabular}{lllllll}
\hline Variable & $\boldsymbol{B}$ & $\boldsymbol{S E} \boldsymbol{B}$ & $\boldsymbol{\beta}$ & $\boldsymbol{R}^{2}$ & $\boldsymbol{\Delta}$ & $\boldsymbol{\Delta R}^{2}$ \\
\hline Activity-oriented & 0.381 & 0.051 & $0.540^{\star \star}$ & 0.313 & $11.776^{\star \star}$ & 0.017 \\
Communication of mission and goal & 0.264 & 0.043 & $0.296^{\star *}$ & & & \\
Incentives & 0.162 & 0.047 & $0.246^{\star *}$ & & &
\end{tabular}

\section{Group factors on the effectiveness of QCC application}

Taking positive organisational performance as the dependent variable Model 1

\begin{tabular}{|c|c|c|c|c|c|c|}
\hline Attitude and ability of the counsellors & 0.538 & 0.040 & $0.539^{\star *}$ & 0.289 & $182.422^{* *}$ & 0.289 \\
\hline \multicolumn{7}{|l|}{ Model 2} \\
\hline Attitude and ability of the counsellors & 0.338 & 0.052 & $0.339^{\star *}$ & 0.338 & $34.051^{\star *}$ & 0.049 \\
\hline Specificity of goals & 0.353 & 0.061 & $0.301^{\star *}$ & & & \\
\hline \multicolumn{7}{|l|}{ Model 3} \\
\hline Attitude and ability of the counsellors & 0.247 & 0.058 & $0.247^{\star \star}$ & 0.352 & $10.925^{\star *}$ & 0.014 \\
\hline Specificity of goals & 0.273 & 0.065 & $0.232^{\star \star}$ & & & \\
\hline Attitude and ability of circle monitor & 0.196 & 0.059 & $0.193^{\star *}$ & & & \\
\hline
\end{tabular}

Taking negative organisational performance as the dependent variable

Model 1

$\begin{array}{lllllll}\text { Attitude and ability of circle monitor } & 0.315 & 0.059 & 0.244^{\star \star} & 0.058 & 28.288^{\star \star} & 0.058\end{array}$

Taking work ability and morale as the dependent variables

\begin{tabular}{|c|c|c|c|c|c|c|}
\hline \multicolumn{7}{|l|}{ Model 1} \\
\hline Attitude and ability of circle monitor & 0.458 & 0.038 & $0.499^{\star \star}$ & 0.248 & $148.192^{\star \star}$ & 0.248 \\
\hline \multicolumn{7}{|l|}{ Model 2} \\
\hline Attitude and ability of circle monitor & 0.276 & 0.049 & $0.300^{\star *}$ & 0.296 & $31.684^{* *}$ & 0.048 \\
\hline Specificity of goals & 0.322 & 0.057 & $0.299^{\star *}$ & & & \\
\hline \multicolumn{7}{|l|}{ Model 3} \\
\hline Attitude and ability of circle monitor & 0.219 & 0.055 & $0.238^{* *}$ & 0.302 & $4.675^{*}$ & 0.006 \\
\hline Specificity of goals & 0.272 & 0.062 & $0.253^{\star \star}$ & & & \\
\hline Training of QCC skills & 0.122 & 0.056 & $0.131^{\star *}$ & & & \\
\hline \multicolumn{7}{|c|}{ Taking employee's satisfaction as the dependent variable } \\
\hline \multicolumn{7}{|l|}{ Model 1} \\
\hline Specificity of objectives & 0.564 & 0.046 & $0.501^{* \star}$ & 0.249 & $149.411^{\star \star}$ & 0.249 \\
\hline \multicolumn{7}{|l|}{ Model 2} \\
\hline Specificity of goals & 0.338 & 0.060 & $0.300^{\star *}$ & 0.297 & $31.465^{\star *}$ & 0.048 \\
\hline Attitude and ability of circle monitor & 0.292 & 0.052 & $0.300^{\star *}$ & & & \\
\hline \multicolumn{7}{|l|}{ Model 3} \\
\hline Specificity of goals & 0.297 & 0.062 & $0.264^{* *}$ & 0.306 & $6.486^{*}$ & 0.009 \\
\hline Attitude and ability of circle monitor & 0.222 & 0.059 & $0.227^{\star \star}$ & & & \\
\hline Training of QCC skills & 0.117 & 0.046 & $0.142^{* *}$ & & & \\
\hline \multicolumn{7}{|c|}{ Taking management mechanism and cultural construction as the dependent variables } \\
\hline \multicolumn{7}{|c|}{ Model 1} \\
\hline Specificity of goals & 0.574 & 0.042 & $0.543^{\star \star}$ & 0.294 & $186.746^{\star \star}$ & 0.294 \\
\hline \multicolumn{7}{|l|}{ Model 2} \\
\hline Specificity of goals & 0.388 & 0.055 & $0.367^{\star *}$ & 0.330 & $25.313^{\star \star}$ & 0.036 \\
\hline Attitude and ability of circle monitor & 0.240 & 0.048 & $0.262^{\star \star}$ & & & \\
\hline \multicolumn{7}{|l|}{ Model 3} \\
\hline Specificity of goals & 0.332 & 0.059 & $0.314^{* *}$ & 0.339 & $6.999^{\star *}$ & 0.009 \\
\hline
\end{tabular}

Continued 


\begin{tabular}{|c|c|c|c|c|c|c|}
\hline Variable & $B$ & SE B & $\beta$ & $R^{2}$ & $\Delta F$ & $\Delta \mathbf{R}^{2}$ \\
\hline Attitude and ability of circle monitor & 0.172 & 0.054 & $0.188^{\star \star}$ & & & \\
\hline Attitude and ability of the counsellors & 0.139 & 0.053 & $0.155^{\star *}$ & & & \\
\hline \multicolumn{7}{|c|}{ Individual factors on the effectiveness of QCC application } \\
\hline \multicolumn{7}{|c|}{ Taking positive organisational performance as the dependent variables } \\
\hline \multicolumn{7}{|c|}{ Model 1} \\
\hline Utility perception & 0.682 & 0.034 & $0.686^{* *}$ & 0.470 & $396.656^{* *}$ & 0.470 \\
\hline \multicolumn{7}{|c|}{ Taking negative organisational performance as the dependent variable } \\
\hline \multicolumn{7}{|c|}{ Model 1} \\
\hline Utility perception & 0.279 & 0.058 & $0.221^{\star *}$ & 0.047 & $22.829^{\star *}$ & 0.047 \\
\hline \multicolumn{7}{|c|}{ Taking work ability and morale as the dependent variable } \\
\hline \multicolumn{7}{|c|}{ Model 1} \\
\hline Utility perception & 0.591 & 0.033 & $0.648^{\star *}$ & 0.418 & $322.051^{* *}$ & 0.418 \\
\hline \multicolumn{7}{|l|}{ Model 2} \\
\hline Utility perception & 0.518 & 0.043 & $0.567^{\star *}$ & 0.426 & $6.890^{* *}$ & 0.008 \\
\hline Willingness to learn new skills & 0.132 & 0.050 & $0.124^{\star *}$ & & & \\
\hline \multicolumn{7}{|c|}{ Taking employee's satisfaction as the dependent variable } \\
\hline \multicolumn{7}{|l|}{ Model 1} \\
\hline Utility perception & 0.614 & 0.035 & $0.644^{\star *}$ & 0.414 & $316.204^{\star *}$ & 0.414 \\
\hline \multicolumn{7}{|l|}{ Model 2} \\
\hline Utility perception & 0.484 & 0.044 & $0.507^{\star *}$ & 0.438 & $20.455^{\star \star}$ & 0.024 \\
\hline Willingness to learn new skills & 0.235 & 0.052 & $0.211^{\star *}$ & & & \\
\hline \multicolumn{7}{|c|}{ Taking management mechanism and cultural construction as the dependent variable } \\
\hline \multicolumn{7}{|c|}{ Model 1} \\
\hline Utility perception & 0.622 & 0.031 & $0.695^{\star *}$ & 0.481 & $415.611^{* *}$ & 0.481 \\
\hline \multicolumn{7}{|l|}{ Model 2} \\
\hline Utility perception & 0.558 & 0.035 & $0.623^{\star *}$ & 0.494 & $12.503^{* *}$ & 0.013 \\
\hline $\begin{array}{l}\text { Willingness to participate in quality and } \\
\text { safety management }\end{array}$ & 0.122 & 0.034 & $0.139^{\star *}$ & & & \\
\hline
\end{tabular}

$B$ is the unstandardised coefficient; SE B is the standard-error of the unstandardised coefficient; $\beta$ is the standardised coefficient. $R^{2}$ is the determination coefficient, $\Delta R^{2}$ is the variation of $R^{2}$ between each model. ${ }^{*} \mathrm{p}<0.05$, ${ }^{* *} \mathrm{p}<0.01$.

QCC, quality control circle.

effectiveness. Each model of the hierarchical regression was equivalent to a multiple linear regression model, $\Delta F$ indicated that $\mathrm{p}<0.001$ for Models 2, 3 and 4; specifically the $\Delta R^{2}$ of the three models was statistically significant.

\section{Influence of group factors on the effectiveness of QCC}

Similarly, all dimensions of the Scale of Group Factors affecting the Application of Hospital QCCs in the questionnaire were divided into independent variables, and all dimensions of the Scale of Effectiveness of Hospital QCCs were divided into dependent variables. A stepwise regression analysis was performed to explore the significance of the regression model and the explanatory ability of the independent variables on the dependent variables.

The results (table 2) show that the attitude and ability of counsellors had a significant explanatory ability on positive organisational effectiveness $(\mathrm{p}<0.01)$. The attitude and ability of the circle monitor were helpful for reducing the negative organisational effectiveness of the application of the QCC $(\mathrm{p}<0.01)$; they also had a significant ability to explain the improvement in work ability and work morale $(p<0.01)$. The specificity of the objectives had significant explanatory ability for the employee's satisfaction, management mechanism and cultural construction $(\mathrm{p}<0.01)$.

The research results fully validated the research hypothesis. The specificity of the attitude, ability and goals of the circle monitor was relatively important among the group factors probably because the circle monitor plays a crucial role in operational processes such as organisation and coordination. The specificity of the goal determines the expected output of the QCC activities and also helps to ensure that team members work together to achieve the shared goal. 
Based on the above research results, the attitude and ability of the circle monitor, the specificity of goals, and the attitude and ability of counsellors are the key group factors that affect the application effectiveness in the process of activity implementation and operations.

\section{Influence of individual factors on the effectiveness of QCC}

Using the same data processing method to divide the individual factors influencing the application of hospital QCCs into each independent variable, we divided the effectiveness of hospital QCCs into the dependent variables. A stepwise regression analysis was performed to explore the significance of the regression model and the explanatory ability of the independent variables on the dependent variables, independent variables with insignificant explanatory power were excluded.

The results (table 2) show that utility perception had a significant influencing ability on positive organisational performance $(\mathrm{p}<0.01)$ and a significant explanatory ability on the reduction of negative organisational performance $(p<0.01)$. At the same time, the utility perception dimension had a significant positive effect on work ability and morale, employee demand, management mechanism and cultural construction $(\mathrm{p}<0.01)$. Based on the above results, utility perception is the most important dimension among the individual factors.

\section{The comprehensive influence of integrated factors on the effectiveness of QCC}

Meaningful background variables were selected from the questionnaire and combined with organisational factors, group factors, individual factors and other dimensions as independent variables. Taking the total mean score of the QCC application effectiveness evaluation scale as the dependent variable, we then performed a regression analysis. To better explain the influence of organisational, group, and individual factors on the application effectiveness of the QCC, the applied regression analysis method was a hierarchical regression (see table 3 for more results). The specific operation process is as follows:

First, the background variables in the questionnaire (including hospital level, location region, circle member's education, job category, professional title, years of work, job nature, circle role and cumulative time of participation in QCC activities) were taken as independent variables, and the correlation analysis was carried out by dividing the total effectiveness evaluation scale of the QCC application into dependent variables. The circle role $(p<0.01)$ and accumulated time participating in QCC activities $(\mathrm{p}<0.05)$ variables were supported as having significant influences on the application effectiveness of QCCs. The other background variables did not have a significant influence and were excluded.

Second, the two baseline background variables, circle role and accumulated time participating in QCC activities that were identified above as having a significant influence on the application effectiveness were taken as independent variables at the first level. Then the total mean score of the organisational factors, group factors and individual factors were introduced layer by layer, and a four level regression model was established.

In this study, the difference between Model 2 and Model 1 was only in the organisational factors as evidenced by the explanatory ability increasing by $28.7 \%(\mathrm{p}<0.001)$ after bringing the organisational factors into the regression, that is, the inclusion of organisational factors was statistically significant for improving the prediction of the QCC effectiveness. Similarly, the inclusion of group factors and individual factors increased the ability to explain the results by $9.9 \%$ and $9.5 \%$, respectively, suggesting a linear correlation between dependent variables and independent variables and indicating that the inclusion of these independent variables is conducive to the prediction of dependent variables compared with the null model.

The results showed that among the three factors on which the study focused, individual factors had the

Table 3 The comprehensive influence of organisational, group, and individual factors on the effectiveness of QCC application

\begin{tabular}{|c|c|c|c|c|c|c|c|c|}
\hline \multirow[b]{2}{*}{ Variable/test value } & \multicolumn{2}{|c|}{ Model 1} & \multicolumn{2}{|l|}{ Model 2} & \multicolumn{2}{|l|}{ Model 3} & \multicolumn{2}{|l|}{ Model 4} \\
\hline & $B$ & $\beta$ & $B$ & $\beta$. & $B$ & $\beta$ & $B$ & $\boldsymbol{\beta}$ \\
\hline Circle role & 0.035 & 0.051 & 0.080 & $0.118^{\star \star}$ & 0.078 & $0.115^{\star *}$ & 0.069 & $0.102^{\star \star}$ \\
\hline Organisational factors & & & 0.413 & $0.548^{\star *}$ & 0.185 & $0.245^{\star \star}$ & 0.131 & $0.173^{\star *}$ \\
\hline$R^{2}$ & 0.013 & & 0.308 & & 0.407 & & 0.502 & \\
\hline$\Delta R^{2}$ & 0.013 & & 0.287 & & 0.099 & & 0.095 & \\
\hline$\Delta F$ & $3.935^{\star}$ & & $191.046^{\star *}$ & & $74.513^{\star \star}$ & & $86.309^{\star \star}$ & \\
\hline
\end{tabular}

$B$ is the unstandardised coefficient; SE $B$ is the standard-error of the unstandardised coefficient; $\beta$ is the standardised coefficient. $R^{2}$ is the determination coefficient, $\Delta R^{2}$ is the variation in $R^{2}$ between each model. ${ }^{*} \mathrm{p}<0.05,{ }^{\star *} \mathrm{p}<0.01$.

QCC, quality control circle. 
most significant influence on the effectiveness of QCCs $(\beta=0.378, \mathrm{p}<0.01)$, followed by group factors $(\beta=0.285$, $\mathrm{p}<0.01)$, and then organisational factors $(\beta=0.173$, $\mathrm{p}<0.01)$. Individual factors had the strongest explanatory ability and the most significant influence on the application effectiveness of QCCs.

\section{DISCUSSION}

This study investigated two dimensions of the application effectiveness evaluation of QCCs and three dimensions that affect the application effectiveness of QCCs.

The evaluation of the application effectiveness of QCCs included two dimensions: organisational effectiveness and individual effectiveness. Organisational effectiveness included positive organisational effectiveness, negative organisational effectiveness, management mechanism and cultural construction. Personal effectiveness had two aspects: one was work ability and morale, that is, the willingness to deal with complicated work immediately and with confidence and the eagerness to cooperate with the other members, and the other was employee satisfaction.

The factors affecting the effectiveness of QCCs included three dimensions: organisation, group and individual. The organisational factors included the attitude of senior hospital leaders, the communication of mission and goal, the way to reward and the orientation of activities. Group factors included target specificity, QCC skill training, councillor 's attitude and ability and circle monitor's attitude and ability. Individual factors included a personal willingness to improve, willingness to learn new skills, willingness to participate in quality and safety management and utility perception.

It is clear from the results that the application effectiveness of QCC was significantly affected by organisational, group and individual factors, among which individual factors played an especially crucial role.

\section{Individual factors and utility perception}

Utility perception, including participants' perception that using QCC can improve work quality, reduce the number and severity of work errors and enhance the understanding of the cause of errors, was found to be the most important dimension among the individual factors. According to Maslow's hierarchy of needs, motivation in psychology was often described as levels like a pyramid. From the bottom of the hierarchy up, the needs are: physical (food and clothing), safety (job security), social needs (friendship), respect and self-actualisation. ${ }^{11}$ The theory distinguishes between lower and higher human needs. The real needs of hospital employees include the basic survival needs of working hard for money, which is low-level need; and the need for professional happiness to achieve self-transcendence at work, and the need for value realisation to gain social recognition and a high evaluation, which are high-level needs. The connotation of utility perception is in line with the practical needs of job self-achievement, ranging from gaining recognition at the top and maintaining a stable career to survival at the bottom within a pyramid model.

The willingness of employees to learn new skills and participate in quality and safety management are also important individual factors. The skills used in QCC activities include learning QC techniques, making charts and slides, writing project articles, executing various activities and so on. Training is one of the common measures of hospital QCCs, ${ }^{910} 12$ and hospitals should carry out a series of regular, professional, precise and practical training. ${ }^{12}$ According to previous research, ${ }^{12-14}$ training should pay attention to results. The needs of different employees should be respected during the training process, and they should not be forced to participate in training for skills they have already mastered to avoid wasting time and discouraging enthusiasm by repeating the training.

\section{Group factors and the attitude and ability of the instructor/ circle monitor}

The explanatory ability of the group factors was stronger probably because the essence of the QCC is teamwork and brainstorming. The attitude and ability of counsellors and circle monitors as well as the specificity of goals are two important group factors. The counsellors should not only have experience in promoting QCC activities but also be willing to fully listen to the suggestions of the circle monitor and circle members. In the process of promoting activities, the counsellors are expected to ensure the continuity of activities and avoid formalisation. The responsibilities of the circle monitor are more focused on communication with team members, including an in-depth understanding and providing effective solutions for handling problems, presiding over the circle meeting and reasonably allocating tasks associated with circle activities. Because counsellors have a higher rank in hospitals, they can effectively integrate resources, lead the team to overcome difficulties in the actual operations and become a strong competitor in resource allocation, thus affecting the effectiveness of the QCC activities. Counsellors and circle monitors are equivalent to the managers and directors of QCC activities. Their attitudes and abilities largely determine the actual effectiveness of the carried out QCC activities. These findings are in line with the actual promotion experience of QCC according to application studies on the effect of QCC in improving medical staff's hand hygiene compliance, ${ }^{12}$ improving the blood collection skill of nurses and the quality of blood specimens, ${ }^{13}$ and improving other spects of medical quality from public news. ${ }^{14}$

The essential characteristics of the QCC are to concentrate on improving things at the basic level (from the perspective of the front-line staff) and to emphasise changing the operational processes and safety culture from the bottom up in a hospital setting. ${ }^{15}$ According to previous research, it is important to give full play to the subjective initiative of the circle members with respect to work ideas. This can improve the circle members' sense of value and ownership of the work and fully mobilise 
their enthusiasm for their work. ${ }^{16} 17$ In addition to encouraging, counsellors and circle monitors also need to strengthen the supervision of the effectiveness and details of all the QCC work and provide a solid backing for the circle members. Objective management theory is one of the foundations of QCC theory. ${ }^{13}$ However, based on the QCC activities practiced in many hospitals, a lot of the target setting focused only on immediate results that could be completed in a few months or a year or two, without any long-term planning. ${ }^{141819}$ In terms of the effectiveness of an activity, it is necessary to further clarify the phased and long-term goals of the work. It is the circle monitor's and circle members' duty to pay attention to forming specific goals and to take measures such as setting the control mode of the implementation process to allow for adjustments when things do not progress as planned, following a specific work schedule, and adopting implementation deadlines.

\section{Organisational factors and activity orientation}

Activity orientation and communicating the mission and goals were the two critical organisational factors. Activity orientation includes setting up or designating the department in the hospital that will be primarily responsible for the QCC, attaching importance to formulating the rules and regulations of QCC activities, carrying out education and training, and holding presentation meetings to acknowledge achievements. These activities are conducive to the standardisation and scientification of the QCC, promoting the exchange of experience, and stimulating the enthusiasm of the circle members, so they are important dimensions for improving the effectiveness of QCC activities. Corresponding institutional guarantees, such as a group incentive system and a system that ensures the implementation of the QCG recommendations, should be provided.

The results of this study showed that organisational factors have significant explanatory power for the effectiveness of QCC activities in medical institutions. Among these factors, activity orientation had the greatest impact at the organisational level, communication had the greatest impact at the individual level and inappropriate rewards had a significant negative impact on the effect of applying QCCs. The research results are consistent with the practical application of the tools in hospitals. Rewards were found to have a significant negative effect on both organisational and individual outcomes, which is contrary to the research hypothesis. According to the theory of organisational contracts, ${ }^{20}$ organisational citizenship behaviour and professional identity can be used to explain the mechanism by which organisational perceptions impact job performance. ${ }^{21}$

One possible reason why the lack of rewards negatively predicted the outcomes is that the sense of identity that arises from QCC activity is the positive emotional connection between the hospitals and the circle members. Another possible reason to explain the unexpected findings is about the potential national cultural differences between the Eastern nations and the West. China's macroscopical incentive approaches such as fiscal and tax were derived from western and market-oriented, ${ }^{22}$ some classic rewards and incentive theories reviewed in this study were from the West. ${ }^{23}$ When the rewards motivated the Chinese hospitals to shape choices, and affected personal involvement in QCC activities, it may correlate differently with western-reported performances. ${ }^{24}$ It is suggested that in a collectivist society, such as China, people are more likely to participate in collective contribution and receive financial rewards if they are in real need and the rewards are in organisational appropriate way. ${ }^{25}$ By providing extrinsic rewards above this emotional connection, the employees may not only feel that participating in the QCC activities is additional work that they are not required to do but may also cause them to doubt the organisation's values or mission. This could lead to a negative cognition and weaken the employee's positive attitude towards QCC activity. Team activities could include team rewards and non-material incentives to improve the collective sense of honour and enthusiasm of the circle members. This attitude of staying on the sidelines may also be transmitted to the individual behaviour of other circle members in that they may protect their own interests from the negative impact of the organisation by reducing their work involvement and cooperation.

In view of the above influential factors, to better promote quality management tools such as the QCC and to improve the effectiveness of their application require the attention of leaders at all levels and must be included into the scope of each hospital's strategic management.

\section{Strengths and Llimitations}

Based on a large number of domestic and foreign literature searches, this study summarised the three key factors affecting the effectiveness of applying QCCs and discussed the mechanism by which QCCs are effective. This research is valuable for the promotion and application of quality management tools such as QCC.

This study focused on exploring the relationship between organisational, group and individual factors in the application effectiveness of QCCs, which differs from the models proposed in previous studies in several important ways. First of all, although other quality-safetyrelated studies may contain some similar structures, such as organisational factors, ${ }^{326} 27$ few studies simultaneously tested the correlations between such a large number of variables in their models and used a hierarchical algorithm to determine whether the factors should be included. There is a gap in the literature addressing the interactive factors of effectiveness in QCC activities. This study's hierarchical algorithm is in line with research highlighting measuring sustainable factors and subfactors in healthcare systems, ${ }^{28}$ helping to prioritise the importance of complicated factors and allocating resources. A second advantage of this study is that previous research did not study the direct effects of different factors on QCC activities using a large population and have rarely designed questionnaires that 
assess the characteristics of QCC activity operation and the ways that they promote QCC adoption. ${ }^{141921}$ Third, in this study, objective personal data collected from questionnaires and hospital indicators were comprehensively evaluated, whereas most previous studies relied on subjective perceptual data as the dependent variable, so their results and suggestions were limited. The framework of this study will help to focus on future operations and promote the effectiveness of QCC activity, which makes up for gap in introducing a new practical effectiveness framework of previous studies. ${ }^{9} 1029$

Although much of the work in this paper was based on previous studies, some limitations can be identified. These primarily fall into the following two categories:

1. Although the reliability and validity of the research tools were good and the sampling method was carefully designed, the sampling group primarily utilised the participants of the sixth National Hospital Quality Control Circle Competition, ignoring other groups that did not participate in the competition or did not enter the finals. However, the purpose of this study was to explore the factors that affect the effectiveness of the application of the QCC. Therefore, what was really needed was data from hospitals that had had a successful QCC application. From an overall perspective the analysis of the results showed no significant differences from the expected results of the study. In the future if conditions permit, a larger-scale sampling of medical institutions at all levels throughout China should be carried out to reduce the error caused by sampling.

2. As a typical cross-sectional research, this study did not establish a cohort or conduct a controlled experiment. To some extent, this means that there is a lack of relevant data that could be used to verify the research results. In the future, cohort or controlled studies can be conducted to increase the credibility of the study, and the research results can be further verified.

\section{CONCLUSION}

Individual factors had the most significant influence on the effectiveness of the application of the QCC. Of the individual factors, the utility perception dimension with the greatest influence had a positive effect on work ability and morale, employee needs, the management mechanism and the cultural construction. Therefore, the process of confirming the QCC effectiveness and that of publishing and advertising the effectiveness of the QCC activities need to receive more attention from the internal hospital administration. The attitude and ability of the circle monitor, the specificity of the goals, as well as the attitude and ability of the counsellor were the key group factors affecting the effectiveness of applying the QCC. Activity orientation had the greatest impact at the organisational level. This study found that inappropriate rewards had a bad effect on team cohesion, so team building should be strengthened.
Therefore, from a bottom-up perspective, it is crucial to arouse the enthusiasm of circle members and even the whole hospital staff to support the QCC activities and to encourage communication of the achievements and experiences. From a top-down perspective, the hospital administration should show how the QCC can build the quality and safety atmosphere in the whole hospital, motivate all the staff to actively participate in the implementation of improvements and give full play to the staff's enthusiasm and creativity. These activities can help hospitals better promote the application of quality management tools, improve the hospital quality and safety system, and ultimately improve the quality of medical services for patients.

Contributors All the authors have met the requirements of participating in the topic selection and design of the paper or participating in the data analysis and interpretation; drafting or revising key theories or other main contents in the paper; revising according to the revision opinions of the editorial department, and being responsible for the integrity. Conception and design of the study was done by DZand TFL. TFL and DZ gave administrative support. DZ and YY were responsible for the provision of study materials. DZ was responsible for collection and assembly of data. Data analysis and interpretation were done by DZ and YY. All authors were involved in manuscript writing and provided final approval of the manuscript. TFL act as guarantor.

Funding This work was supported by Youth fund of the National Natural Science Foundation of China [Grant No. 72004112], the Humanities and Social Sciences Foundation of China Ministry of Education [Grant No. 19YJCZH239] and Shenzhen educational science 2020 annual planning project [Grant No. ybzz20034]; This work was also a project of Shenzhen Key Research Base of Humanities and Social Sciences (Social governance and Innovation Research Center of Tsinghua Shenzhen International Graduate School)

Competing interests None declared.

Patient and public involvement Patients and/or the public were not involved in the design, or conduct, or reporting or dissemination plans of this research.

Patient consent for publication Not applicable.

Ethics approval The data that support the findings of this study are originally collected by Institute for Hospital Management of Tsinghua University. This study conducted the data analysis with the permission of Tsinghua Shenzhen International Graduate School Medical Ethics Committee and maintained the confidentiality of the data. As this study did not contain any studies with human patients performed by any of the authors, and this study didn't include any personal identifying data or patients' information, formal ethics approval was not required for this research and was exempted for this study.

Provenance and peer review Not commissioned; externally peer reviewed.

Data availability statement Data are available upon reasonable request. Data are not publicly available due to legal restrictions and confidential nature of the data, but are available upon reasonable request. Requests may be sent to the Institute for Hospital Management of Tsinghua University.

Open access This is an open access article distributed in accordance with the Creative Commons Attribution Non Commercial (CC BY-NC 4.0) license, which permits others to distribute, remix, adapt, build upon this work non-commercially, and license their derivative works on different terms, provided the original work is properly cited, appropriate credit is given, any changes made indicated, and the use is non-commercial. See: http://creativecommons.org/licenses/by-nc/4.0/.

ORCID iDs

Dan Zhang http://orcid.org/0000-0002-5699-752X

Yue Yan http://orcid.org/0000-0001-9434-4223

\section{REFERENCES}

1 L-r W, Wang Y, Lou Y. The role of quality control circles in sustained improvement of medical quality. Springerplus 2013;2. 
2 Burke C, Webster K. Developing a clinical management tool to evaluate quality. Nurs Manage 2013;20:14-18.

3 Yousefie S, Mohammadi M, Monfared JH. Selection effective management tools on setting European foundation for quality management (EFQM) model by a quality function deployment (QFD) approach. Expert Syst Appl 2011;38:9633-47.

4 Bahadori M, Teymourzadeh E, Faizy Bagejan F, et al. Factors affecting the effectiveness of quality control circles in a hospital using a combination of fuzzy VIKOR and grey relational analysis. Proceedings of Singapore Healthcare 2018;27:180-6.

5 JJ M, Shen HM, Lv B. Study on the effect of quality control circle activities on hospital infection control. International Journal of Clinical and Experimental Medicine 2021;14:2110-6.

6 Hosseinabadi R, Karampourian A, Beiranvand S, et al. The effect of quality circles on job satisfaction and quality of work-life of staff in emergency medical services. Int Emerg Nurs 2013;21:264-70.

7 Kitazawa K, Osada H. Incremental innovation and management styles of group activities: an empirical study on Tangible and Intangible effects by quality control circle activities. Conference of PICMET - Technology Management for Emerging Technologies (PICMET); 2012 Jul 29-Aug 02, Vancouver, CANADA2012, 2012.

$8 \mathrm{Ndu}$ AE, Udensi. Quality (control) circle: the Nigerian experience.

9 Tingfang L. Review on QCC of Chinese hospitals. Chinese Hospitals 2015;19:1-3.

10 Tingfang WC LIU. Theory and practice characteristics of task achieving QCC. Chinese Hospitals 2017;21:45-9.

11 Gawel JE. Herzberg's Theory of Motivation and Maslow's Hierarchy of Needs. ERIC Clearinghouse on Assessment and Evaluation 1997.

12 ZHANG Dan LT. Problems on strategy formulation of hospital quality control circles and its countermeasures Chinese hospitals 2015;19:10-14.

13 Li Chunxiang WB, Fengying K. Analysis of history and development status quo of quality control circle. Chinese Nursing Research 2017:31:1140-2.

14 SL-d WW-wen, Hai-yan C. The application of quality control circle in the safety management of oral medication administration. Journal of Nursing Administration 2014:14:358-60.

15 Haini J, tingfang L. Problems and countermeasures of hospital quality control circle topic selection in China. Chinese Hospitals 2015;19:4-6.

16 Hongxiu W, lei T, Meixiu G. The existing problems and countermeasures of quality control circle activities in the process. Journal of Nursing Science 2016;31:75-7.
17 Hassmiller SB, Bolton LB, Burnes BL. The development of TCAB: an initiative to improve patient care and nursing retention. Am J Nurs 2009;109:4.

18 Huang $\mathrm{C}$, Qin $\mathrm{H}$. The effects of quality control circle on decreasing the unplanned extubation incidence among ICU patients with endotracheal intubation. Chinese Nursing Management 2013;13:47-9.

19 YUAN Xuanhua ZL, Hongyu XU, et al. The influence of quality control circle activities on reducing the unplanned extubation rate of indwelling gastric tube in pediatric general surgery. Today Nurse 2020;27:187-9.

20 Gao Zhonghua ZC. Can organizational politics in the workplace harm employee performance? from the perspective of individualorganization theory. Acta Psychologica Sinica 2014;46:1124-43.

21 ZHANG Bin QZ-y LIA. Effect of perceived organizational support and professional identity on OrganizationalCitizenship behavior in nurses. Journal of Nanchang University(Medical Sciences) 2015;55:86-90.

22 BY L, Liu YZ, Li Y. Fiscal incentives, competition, and investment in China. China Economic Review 2020;59.

23 Akerlof GA, Kranton RE. Identity and the economics of organizations. Journal of Economic Perspectives 2005;19:9-32.

24 Mark G, Smith AP. Occupational stress, job characteristics, coping, and the mental health of nurses. Br J Health Psychol 2012;17:505-21.

25 Hsee CK, Weber EU. Cross-National differences in risk preference and lay predictions. J Behav Decis Mak 1999;12:165-79.

26 Nadziakiewicz M, Mikolajczyk A. The quality and safety of health care services. Management Systems in Production Engineering 2019;27:100-4.

27 Anelo TFD, Caregnato RCA. Educational action for hospital safety: cleaning and disinfection of the environment in the immediate vicinity of the patient. Vigilancia Sanitaria Em Debate-Sociedade Ciencia \& Tecnologia 2018;6:89-95.

28 AlJaberi OA, Hussain M, Drake PR. A framework for measuring sustainability in healthcare systems. Int $J$ Healthc Manag 2020;13:276-85.

29 Tzortzopoulos A. Implementation of the principles and tools of Total Quality Management in the health-care sector - guarantee of quality improvement of hospitals and the National Health System. Archives of Hellenic Medicine 2018;35:649-64. 